\title{
Modelling process integration and its management - case of a public housing delivery organization in United Arab Emirates
}

\author{
Senthilkumar Venkatachalam ${ }^{1 *}$, Fikri Diweiri ${ }^{2}$, and NouraAl Suwaidi ${ }^{3}$ \\ ${ }^{1}$ Sustainable Construction Materials and Structural Systems Research Group, Department of Civil and \\ Environmental Engineering, University of Sharjah, Sharjah, United Arab Emirates \\ ${ }^{2}$ Department of Industrial Engineering and Engineering Management, University of Sharjah, \\ Sharjah, United Arab Emirates. \\ ${ }^{3}$ Innovation and Futurism Office, Directorate of Housing, Sharjah, United Arab Emirates
}

\begin{abstract}
Huge volume of project information are generated during the life cycle of an AEC projects. These project information are categorized in to technical and administrative information and managed through appropriate processes. There are many tools such as Document Management Systems, Building Information Modeling (BIM) available to manage and integrate the technical information. However, the administrative information and its related processes such as the payment, status, authorization, approval etc. are not effectively managed. The current study aims to explore the administrative information management process of a local housing delivery public agency. This agency manages more than 2000 housing projects at any time of a year. The administrative processesare characterized withdelivery inconsistencies among various project participants. Though there are many commercially available process management systems, there exist limitations on the customization of the modules/ systems. Hence there is a need to develop an information management system which can integrates and manage these housing projects processes effectively. This requires the modeling of administrative processes and its interfaces among the various stakeholder processes. Hence this study aims to model the administrative processes and its related information during the life cycle of the project using IDEF0 and IDEF1X modeling. The captured processes and information interfaces are analyzed and appropriate process integration is suggested to avoid the delay in their project delivery processes. Further, the resultant model can be used for effectively managing the housing delivery projects.
\end{abstract}

\footnotetext{
*Corresponding author: svenkat@sharjah.ac.ae
} 


\section{Introduction}

Construction projects are complex endeavors that require multiple stakeholder's involvement to accomplish the expected project outcomes [1]. It is further characterized by its components, people and processes variations and its complex relationships and interfaces [2]. This characterization brings a socio technical complexities to the project delivery. These complexities are characterized in all aspects of projects, including organization structure, procedures, technology etc., [1]. Further these complexities influence the management capabilities of project stakeholders in terms of project team selection, planning, coordination and selection of procurement arrangements, characterizing them as one of the most complex undertakings for any project delivery. Therefore, understanding and managing complexities is essential to achieve satisfactory performance of construction project delivery [3]. Millions and millions of project information are produced during the construction projects. Management of these information play a vital role on addressing the complexities and its knock-on challenges appeared technically and administratively.

The use of information technology (IT) has been demonstrated to be capable of managing the project information, however prior to recent times has been largely discrete. However, the recent CAD working platforms such as Building Information Modeling (BIM) to exchange the information has enhanced the communication and collaboration in the technological side mostly [4][5][6]. The administrative information exchange and collaboration is been managed through companywide ERP systems and other document management systems but pose challenges on the data security and customization to the local needs. Hence there exists a need to the development of new information management system to improve productivity on the delivery of information through effectively processing and providing necessary information. Further, it also supports organizations to achieve efficient work performance. An information system is a structured collection of information resources, information technology, people and all activities that works in coordination to achieve definite objectives in the business organization. As information technology is essential and vital to business, the development of an information system in the organization becomes critical for the success of the organization. However extracting the various relationships such as functional, technical and administrative is vital to the success of this Information System. This paper explains the step by step procedure adopted in a governmental Housing Delivery Organization called Department of Housing (DH) with the aim of identifying the information and process flow among the various stakeholders with DH projects and develop an appropriate method to effectively manage the information to avoid inefficiencies in their housing project delivery. The following section outlines the current status of DH's project delivery process and its need towards an Information Management System. This is followed by the development of IDEFO models to capture the various interfaces among the project processes. The theoretical validation is reported to get the initial feedback against the developed systems followed by the summary and conclusions.

\section{Housing development organization background}

$\mathrm{DH}$ is one of the various establishments under the state government. DH's core business is to provide people with financial aid. DH consists of three main departments, which are Housing Applications Department (HAD), Engineering Services Department (ESD) and Project Management Department (PMD). The housing application department receive, review, study and approve the application from the beneficiaries. Then the engineering services department aids the approved applicant to choose a suitable design and to establish 
a contractor among the three parties. Then the project management department supervisesthe work on the approved applicant's site to assure quality and performance of the contractor. One of the sub objectives of the DH includes the assistance of obtaining low cost contract for its beneficiaries, hence theDHprojects are considered as low cost and small scale projects. Currently the DH manages more than 2000 running projects with limited number of employees, there exists challenges on managing the project progress information and its related transactions during the execution of their government sponsored (Grant) projects. The timely delivery of these transactions are critical and delays will result in contractors/consultants dissatisfaction which leads to the non-participation of contractors/consultants to Grant based DH projects. The project management department has been advocated to address this problem. In order to understand the root cause of the problem, the PMD conducted interviews and questionnaire survey followed by the statistical analysis on the responses obtained to identify the root cause of the problem. However due to the length restrictions of the paper, the detailed statistical analysis is not been included within the scope of this paper. However, a brief about the results obtained is been discussed to justify the improvement processes.

\section{Analysis on the current status and processes of project delivery in $\mathrm{DH}$}

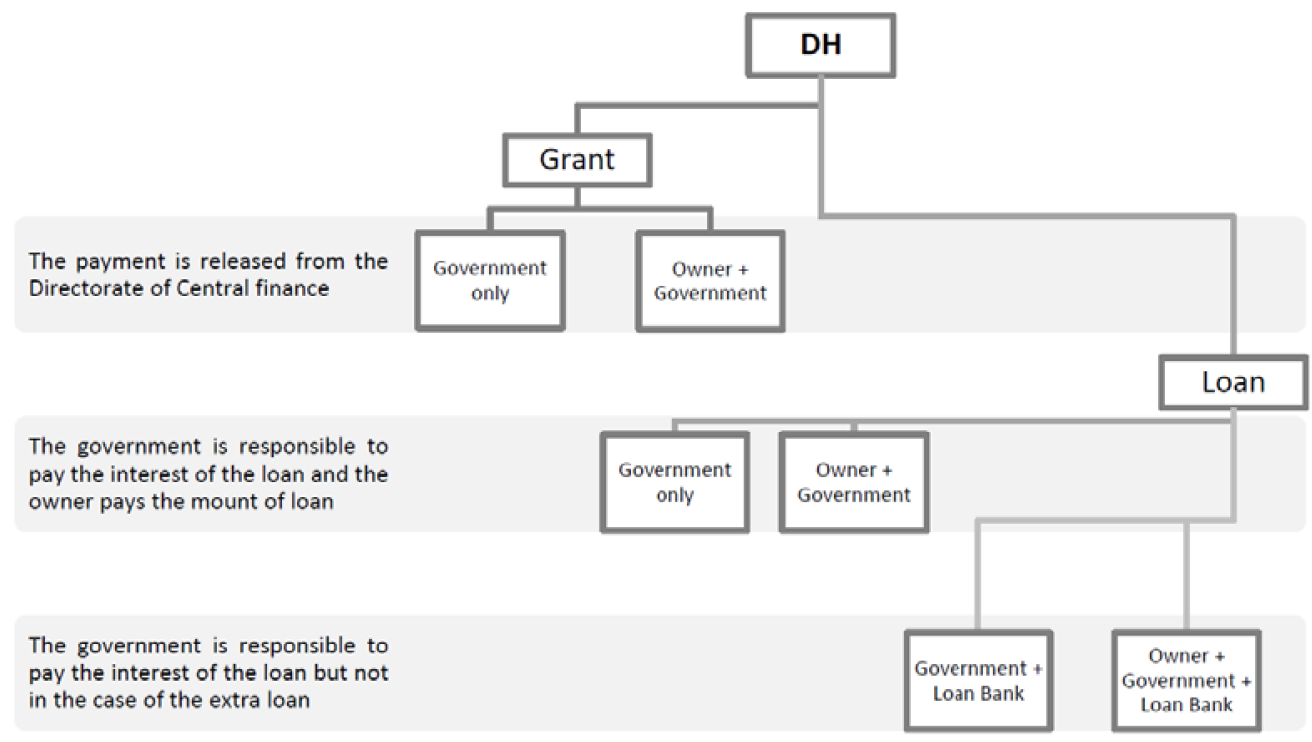

Figure 1. Types of project delivery in DH based on various financing options

Figure 1 illustrates the types of project delivery that the $\mathrm{DH}$ is practicing, mainly based on the type of financing options such as loan and grants at the higher abstraction level. Many projects were executed through the Grants route and the same were experiencing the problem mentioned in the previous section. The current project processes and its delivery status on the DH's projects were asked to the contractors and consultants who works for the $\mathrm{DH}$ projects. The information is obtained through semi structured focus group interviews about the various processes and project delivery status. Based on the interview, along with the documental evidences the various processes and its delivery status were summarized. The summarized data were presented in the form of a process diagram to the contractor and 
the consultants and revised according to the real world practice. Further based on the focus group interview it was revealed that the payment approval processes were delayed a most to impede the project delivery. Various reasons/ causes were listed by the respondents, the same were captured through a cause and effect diagram as shown in figure 2.

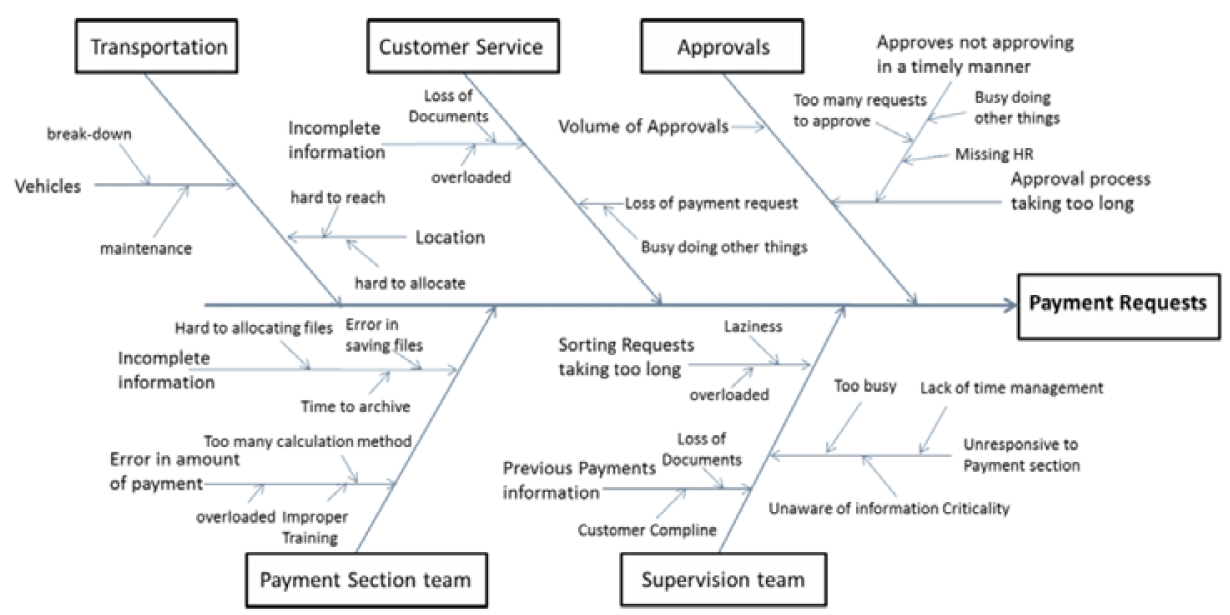

Fig. 2. Cause and effect diagram on factors influencing the payment processes.

Further to identify the important influential causes, a sample of 50 completed projects consists of 24 loan projects and the 26 grants projects were analyzed statistically based on its time taken on various project life cycle processes on each of the above depicted causes. The descriptive statistics results showed that the approval process taken more than the prescribed 10 days by the DH. Further, one-way ANNOVA test was conducted to identify the correlation between the different causes and the delay. For example, customer service employees are accountable for delivering the completed form on time, including full documents requested by the payment section. A one-way ANOVA Test was conducted between "the time taken to send the completed document from the customer service section to the payment section" versus total time spent on the payment process to measure the customer service team's impact of delay in their processes. The results of the test, has a pvalue of 0.000 and R-sq.of 65.07 percent. Which confirms the moderate correlations. Hence the customer service process need improvement. Further with the same One-way ANOVA tests with respect to the other causes, revealed that the Approval and the Supervision processes had a significant correlation to the delay in project payment delivery time and hence need improvement.

\section{Development of the framework for Information management system}

To improve the existing processes the $\mathrm{DH}$ processes are captured through the functional modeling method called IDEFO [7]. In order to develop a new system with the improvedprocesses flow, the system need to be defined by its requirements and specify the various functions in order to design and develop the system that performs the intended purpose. With this intention the Different IDEFO models of the existing DH system is captured at various hierarchical levels and depicted in figures 3 to10. After this, the information modeling at various processes are captured through IDEF1X, it is a semantic 
data modeling technique which captures information and its interactions [8] to modify the process flow effectively.

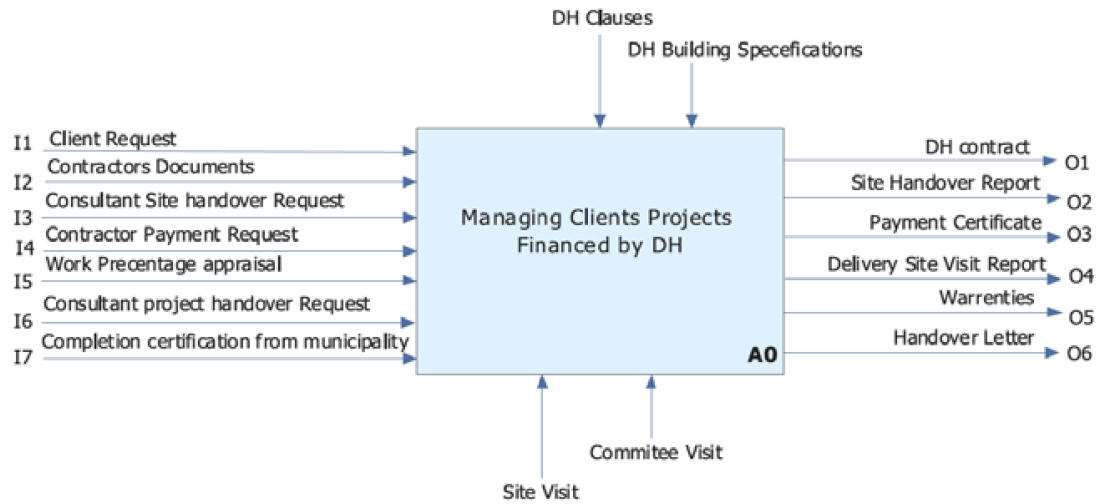

Fig. 3. Top level context diagram Node-AO managing client project financed by DH.

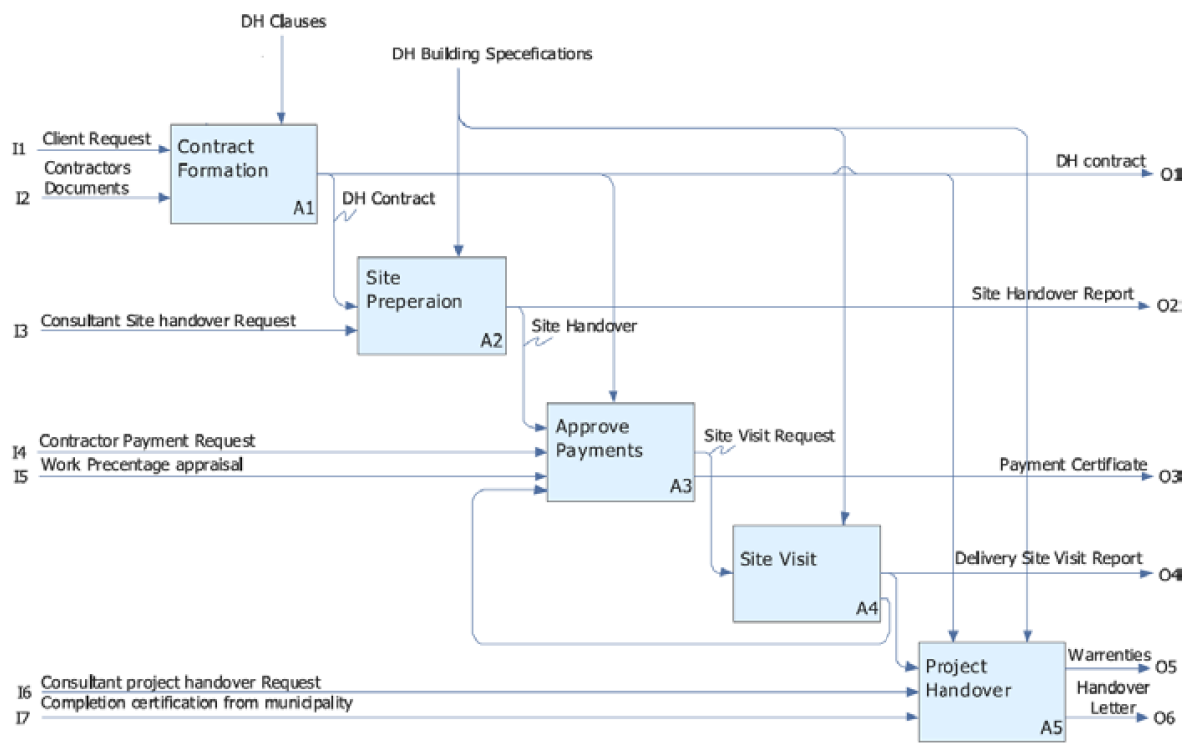

Fig.4. Decomposition of Node-AO- managing client's projects financed by DH. 


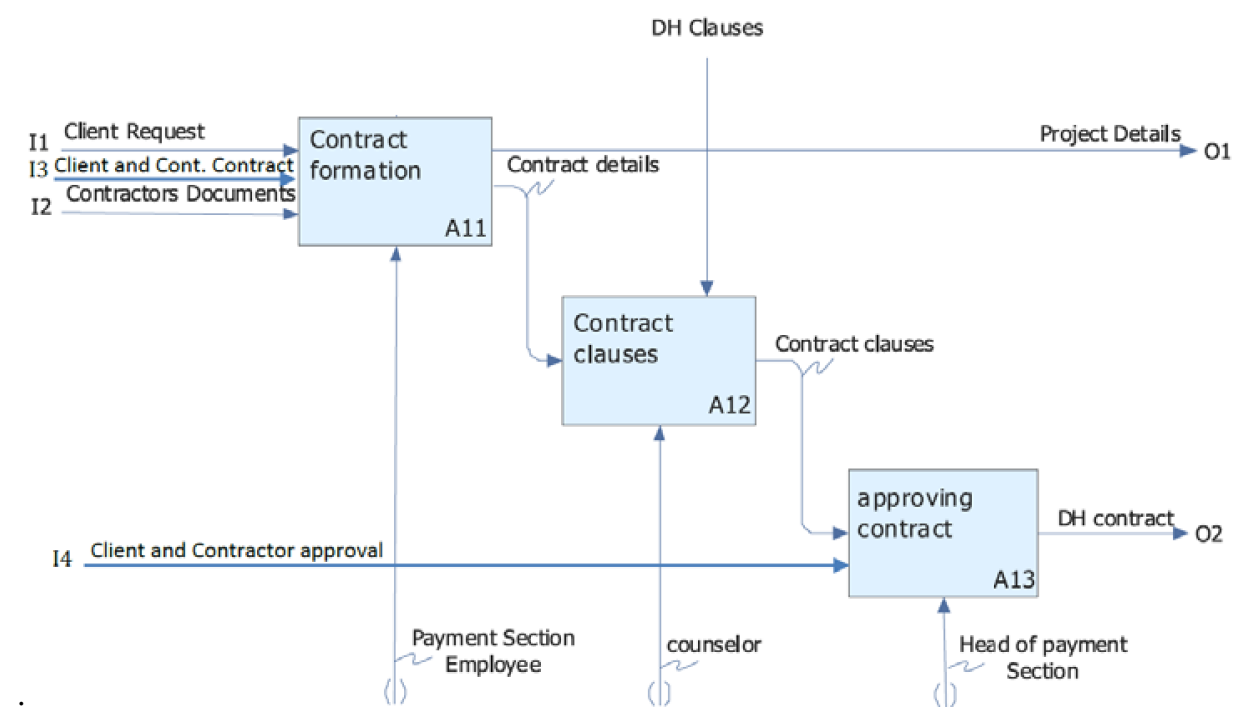

Fig.5. Decomposition of Node-A1.

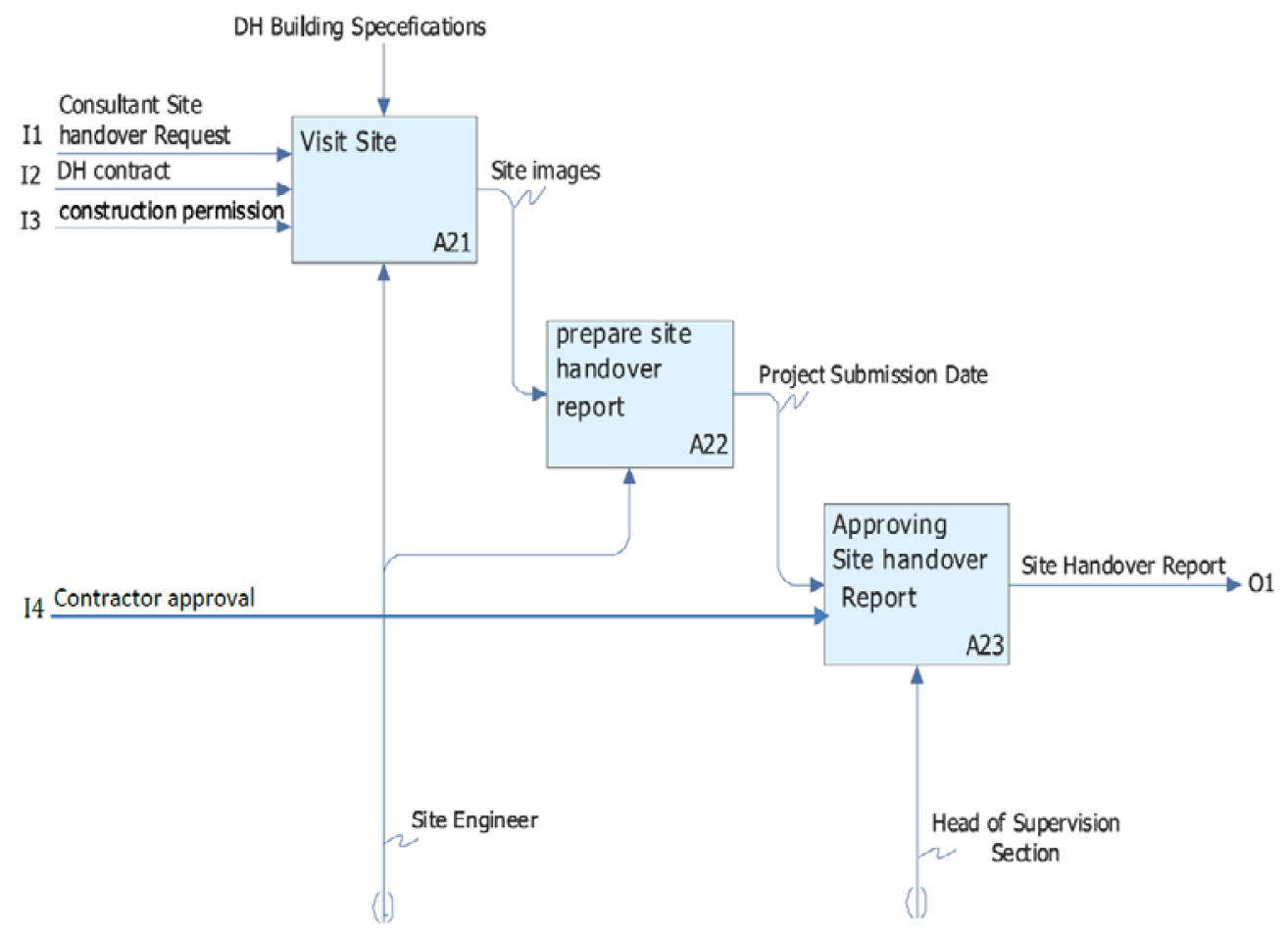

Fig.6. Decomposition of Node-A2. 


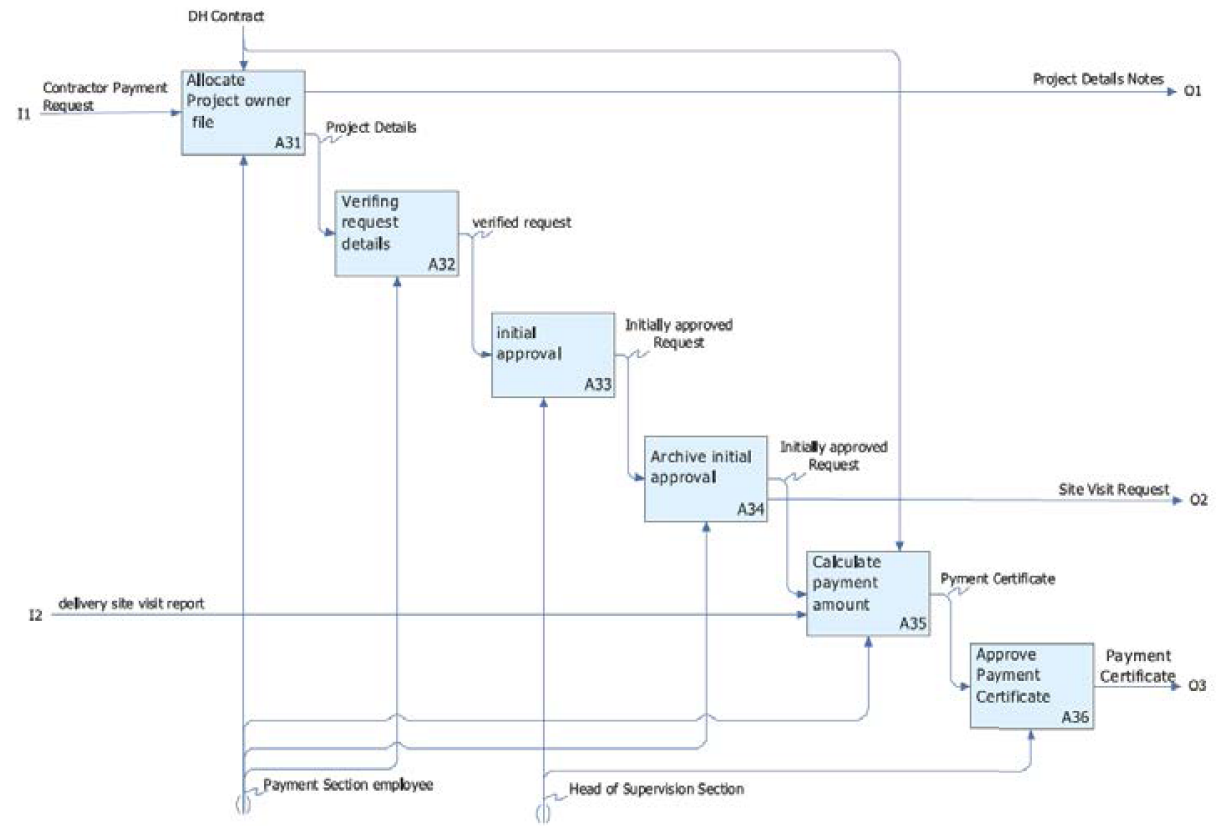

Fig.7. Decomposition of Node -A3.

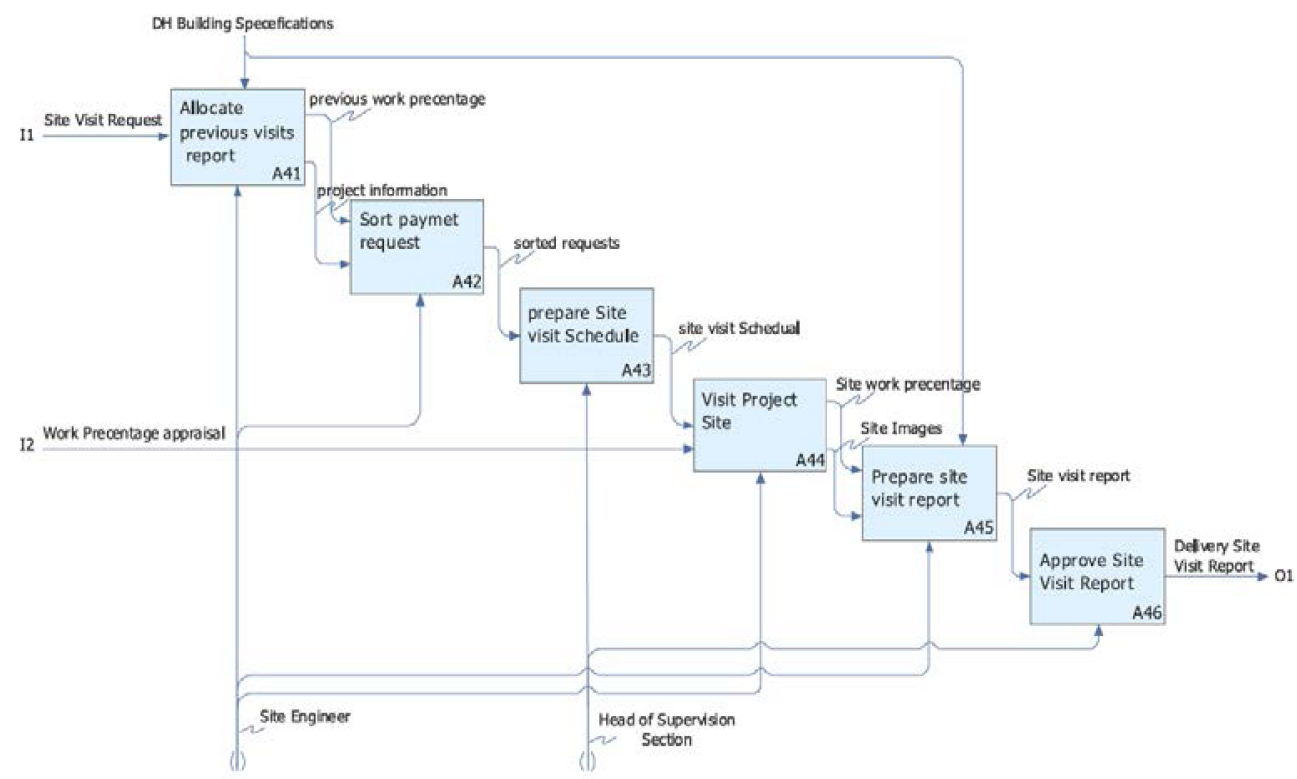

Fig.8. Decomposition of Node-A4. 


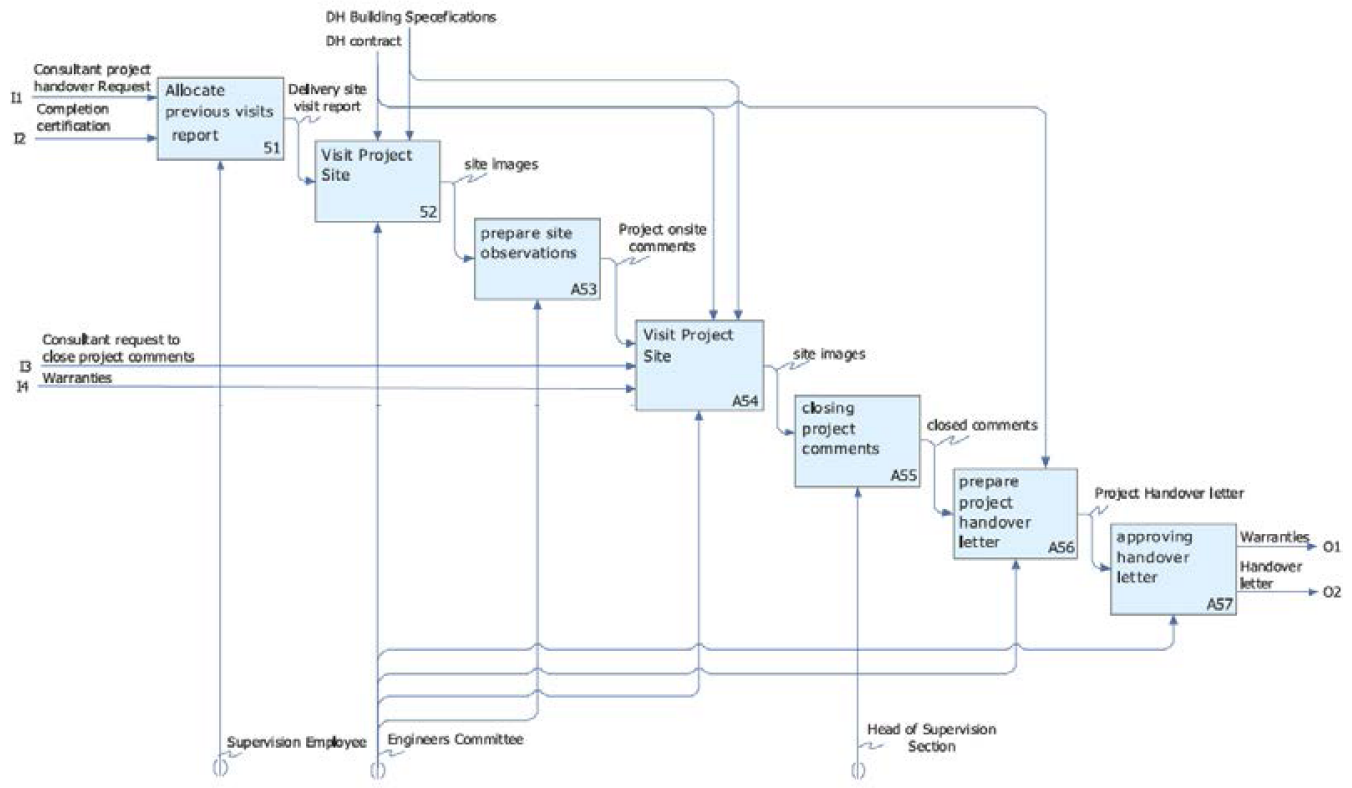

Fig.9. Decomposition of Node-A5.

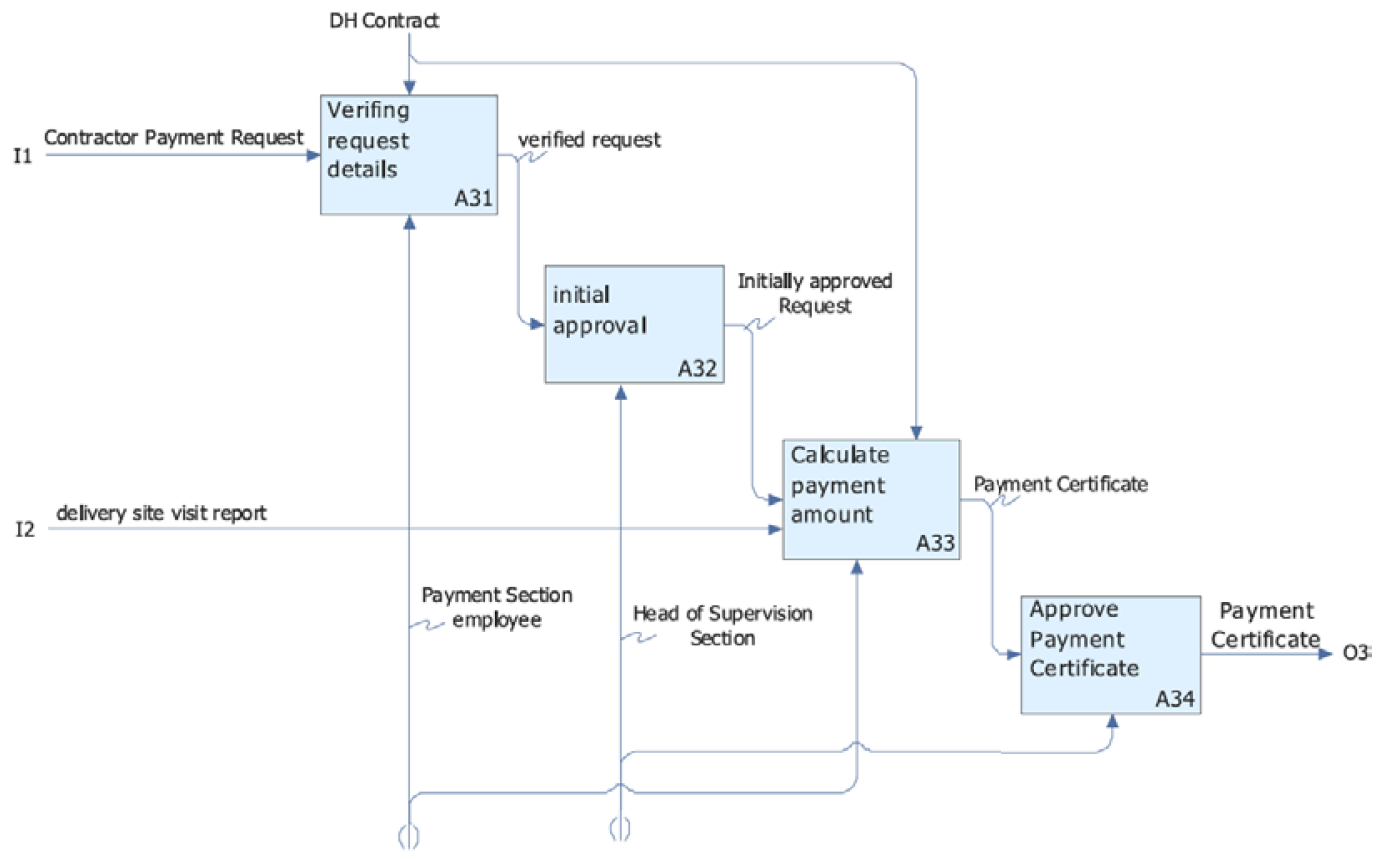

Fig.10. Modified Node-A3. 
The overall activity is described in Figure 3 as managing clients' projects. The client request to manage the project is input to this activity along with contractor payment request during the construction, which is input for the payment certificates in order to finally handover the project (handover letter). In addition, the activity provides an information output, Site HandoverReport and Delivery Site Visit Reports. DH Clauses and Building Specifications control this activity the decomposition of node A0 is shown in Figure 4. Activity Contract Formation (Node A1), is the first project preparation step. The DH Clauses controls this activity, which yields to the final contract between three parties DH, Client and Contractor (DH contract) as shown in Figure 5. Activity Site preparation (Node A2), is the second preparation step for a project financed by DH as shown in Figure 6. The DH building specifications controls this part, which leads to Site handover to the contractor (Site Handover Report). The subsequent activities of Approve Payments, Site Visit and Project Handover are represented in a similar manner during the following stages of the project. Each has an information input and output requirements. Also, each activity is guided by the clauses given in the DH contract as shown in Figures 6 to 9 respectively.

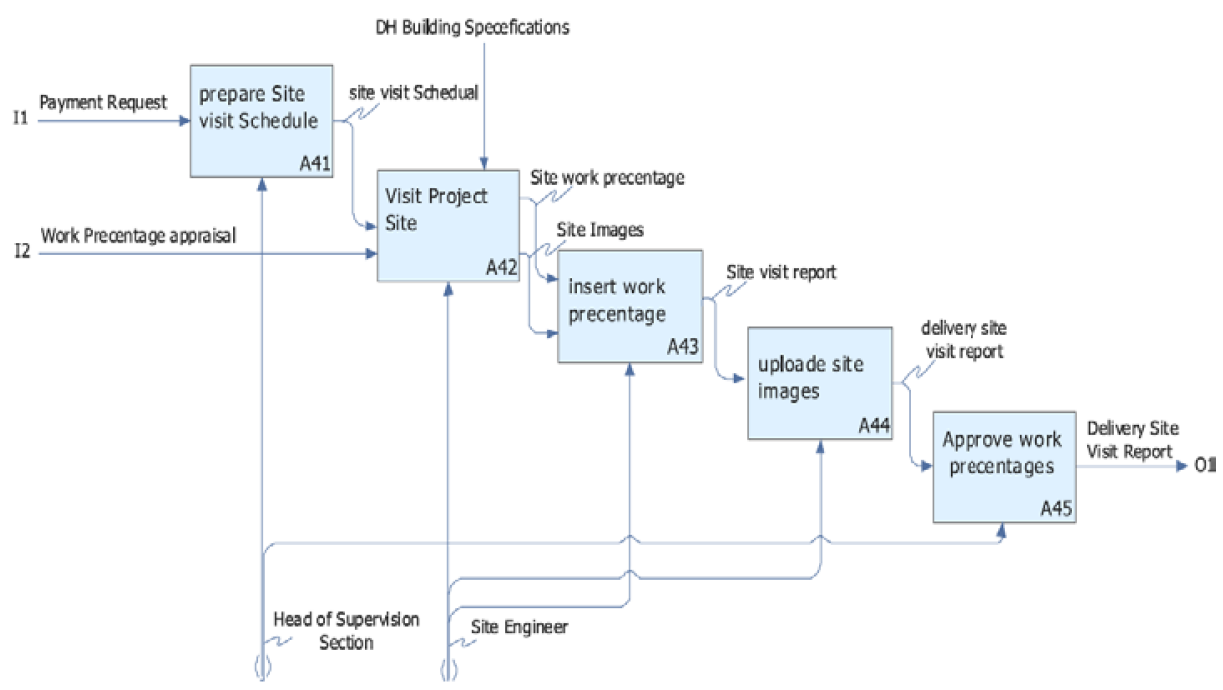

Fig.11. Modified Node-A4. 


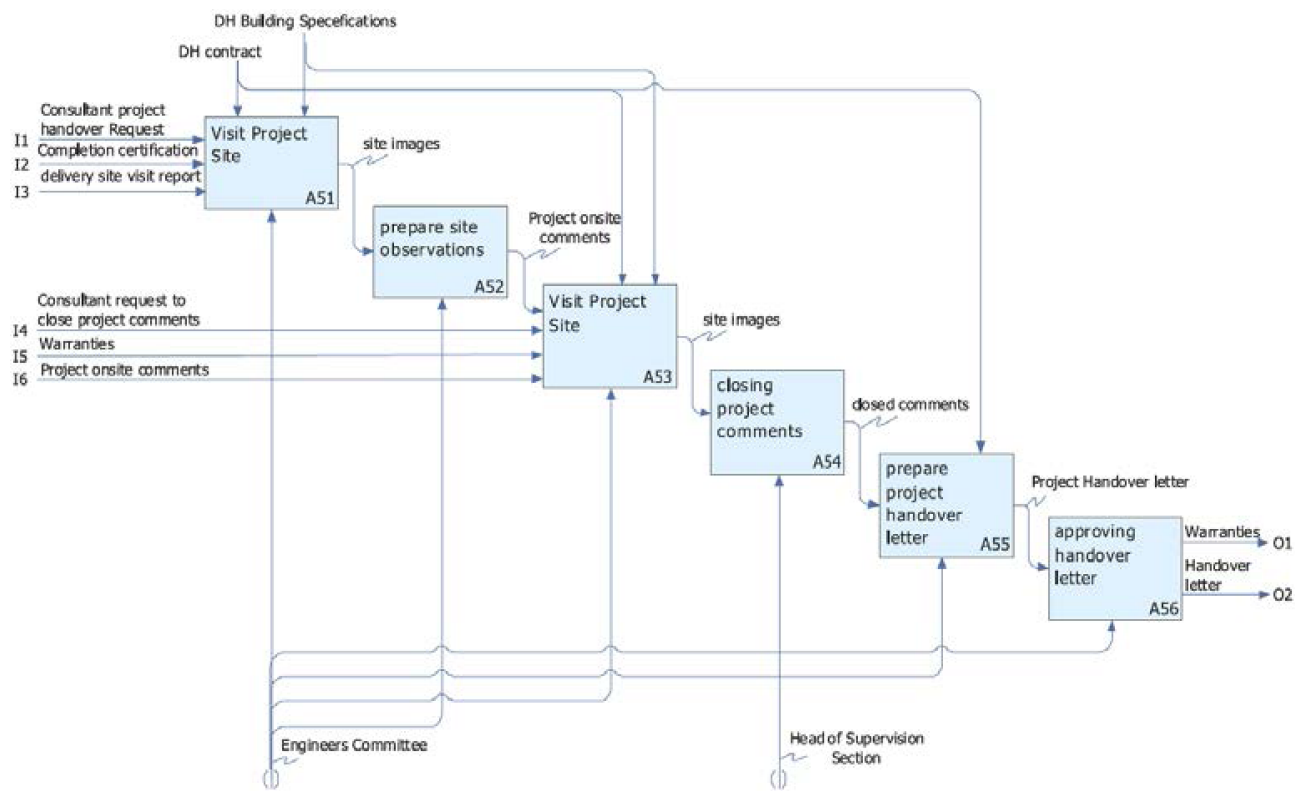

Fig.12. Modified Node -A5.

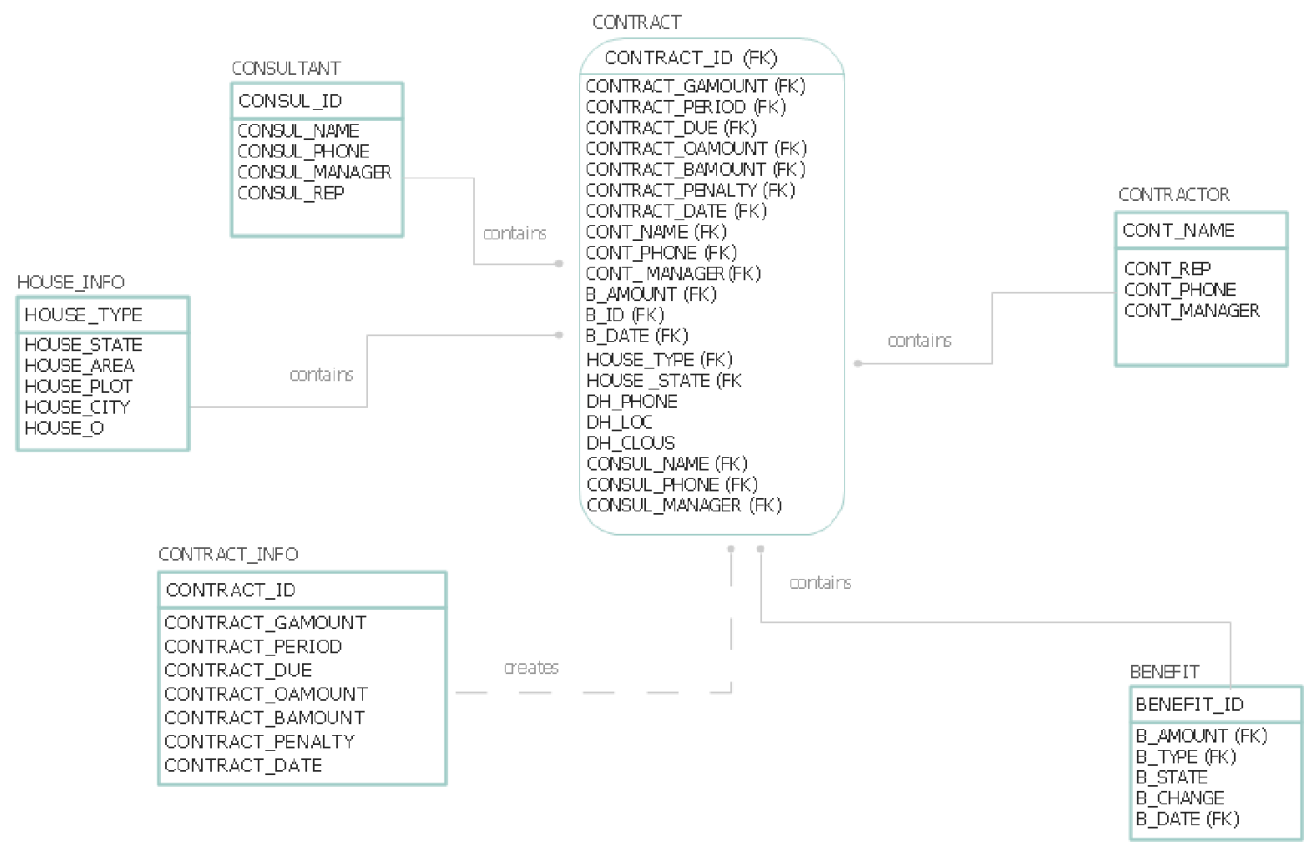

Figure 13. IDEF1X for contract information.

In activity A11, Forming Contract, the payment section employee forms the DH contract after he/she receives a request from the client with the respective contractor documents. Then the contract details is written according to the Client and Contractor contract. In activity A12, Contract Clauses, the Counselor forms the contract according to the contract details, where the DH Clauses controls this activity. Finally, contract is approved in A13, upon contract approval, the payment section employee requests client and contractor to sign the contract in presences of Head of Payment Section to finally establish 
a contract between the mentioned three parties (DH Contract), and a copy is sent to Supervision Section.

The decomposition of node A2 is shown in figure 6, called Site Preparation. The process begins with A21, Visit Site, where site engineer receives a request from consultant to handover the site. Site engineer visit the site and take site images to make sure that there is no existing structure/ construction at the site. In A22, Prepare Site handover Report, the site engineer prepares the handover report, which is an information output; the date to handover the project is indicated along with other project information. In A23, head of supervision section approve the report along with the contractor approval. Then the Site Handover Report is submitted to the consultant and the contractor of the project.

Figure 7 shows the decomposition of node A3. In A31, the contractor request for payment of his project is the input to this activity. Payment section employee allocatesa project file through the existing contract and named after the owner. In activity A32, verifying request details, the details written in request is verified based on the information recorded in project folder. The initial approval for payment request is obtained in A33 from head of payment section. In A34, payment section employee archives initial payment approval. In activity A35, calculate payment amount, delivery site visit report is an input to this activity where the payment employee have to calculate the payment amount and project DH contract controls this activity. Head of payment section approve payment amount in A36 to finally have an approved payment certificate for the contractor request.

Figure 8 shows the decomposed activity steps of node A4, Site Visit. In A41, site visit request is the input to this activity. The supervision section have to allocate the project file and the output of this activity is previous work percentage and project information. In A42, the site engineer sort the site visit requests according to his allocated area. In A43, prepare site visit schedule, in which, head of supervision section establish a site visit schedule according to the sorted site visit requests. Site engineer visit the project site in A44 to determine initial work percentage and verify it by capturing site image. In activity A45, site engineer prepares site visit report to specify each work percentage category and attach site images for each category, in which DH building specification controls the activity. Head of supervision section modifies and approve site visit report in A46 and the output of this activity is delivery site visit report which is sent to payment section.

Figure 9 shows the decomposition of node A5, Project Handover. In A51, consultant project handover request along with completion certificate from the municipality, is an input to this activity. Supervision employee allocates previous delivery site visit report to verify that work percentage appropriate for handover. In activity A52, engineers committee visits the project site, in which again DH contract and building specification controls to this activity. In A53, committee prepares site observation and the output is project onsite comments. Comments are drafted by head of committee and if all the necessary progress is been made then the head prepares project handover letter.

The IDEF0 model of the basic elements of the functional process "as is "in DH is presented in the previous section. To verify the same, the authors showed the same functional model in the form of a flow chart with appropriate details to the $\mathrm{DH}$ employees involved in the housing delivery processes and necessary modifications and additions were administered accordingly. Further, they also agreed that the boundaries of the system defined by the IDEF0 model are acceptable. Although, it is possible to carry out the decomposition of the IDEFO to further smaller abstraction level to for further more detailed modeling, the authors decided to stop this level as the model has given an appropriate level of understanding of the DH's housing delivery process. With these input, the information management system is developed through an IDEF1X model [8]for its relational database design for the proposed system as shown in figure 13. The figure 13outlines the contract formation and the relationship between different information and 
also gives an insight into the data that has to be captured with each contract and its relationship/ interfaces with other data generated during the delivery process.

Based on the data information modeling through IDF1X, the "to be IDEFO" functional modeling is developed in order to have an integrated process to manage the DH delivery process efficiently. After the development of the complete information model (IDEF1X), the final functional model (IDEF0) is developed. In the DH case, the nodes A3, A4 and A5 are modified as the A1 and A2 doesn't require any modifications. Some of the redundant functions are removed in the "to be" model and some of the necessary functions are added accordingly to encourage the process and information integration. Figures 10, 11 and 12 depicts the modified IDEFO functional model. The revised model removed the redundant functions/ processes as a result of the proposed information management systems and its information integration. For example, the redundant function such as "Allocate Project owner File" and "Archive Initial Approval" in the as is model is been removed in the A3 node as the information system database has the details in the central database. Similarly in the A4 node the processes had been modified as the information system has the inbuilt automated reporting function through uploading the percentage complete and the related site images.

\section{Discussions and conclusions}

This project demonstrates the identification of the process inefficiencies in the housing delivery organization through a cause and effect diagram. The analysis revealed that the customer services approval and supervisory process in the DH need improvement in their delivery process. The DH project delivery is then explored further by capturing the processes using IDEFO, which helped the authors to understand the functions, participant processes and their interrelationships. The developed functional model is then used to develop an IDEFX1 information / data model to assist the development of relational data base to the proposed information management system. With the IDEFX1 models the functional models are modified to avoid the redundant processes which exists in the DH delivery process and the appropriate "to be" functional models are generated for the efficient project process integration and the delivery. Though there are many information system available in the market to use and tailor made the need, the development of an inhouse system is advantageous due to many reasons such as the opportunity for its customization/ modifications, data security etc. Further study on decomposing the functions in to lower level may improve the system, as well as the interoperability among the different technical tool with the proposed system need to be explored further. Due to the length constraints of the paper, the authors are limited to only present the process integration and management steps. The development of Information Management System and its validation can be demonstrated in future work.

\section{References}

1. C.Fang, and F. Marle, Dealing with project complexity by matrix-based propagation modelling for project risk analysis. Journal of Engineering Design, 24(4), 239256.(2013)

2. D. Antoniadis, F. Edum-Fotwe, A. Thorpe, and R. McCaffer, R,Exploring Complexity in Construction Projects.1-6.(2008).

3. D. D. Gransberg, J.S. Shane, K. Strong,and C.L. del Puerto, Project Complexity Mapping in Five Dimensions for Complex Transportation Projects. Journal of Management in Engineering, 29(4), 316-326 (2013). 
4. C. Dossick, and G. Neff, Organizational Divisions in BIM-Enabled Commercial Construction.Journal of Construction Engineering and Management, 136(4), 459-467, (2010).

5. A. Grilo, and R. Jardim-Goncalves, Value proposition on interoperability of BIM and collaborative working environments,Automation in Construction, 19(5), 522-530, (2010).

6. A. Porwal, and K.N. Hewage, Building Information Modeling (BIM) partnering framework for public construction projects. Automation in Construction, 31, 204-214, (2013).

7. G. Varun, William J. Kettinger,Process Think: Winning Perspectives for Business Change in the Information Age. 168, (2000).

8. T. Bruce, Designing Quality Databases with IDEF1X Information Models. New York: Dorset House, (1992). 